\title{
Effects of Annealing Temperature on Structural and Optoelectronic Properties of Zr-doped ZnO Thin Films for Photosensors
}

\author{
Ming-Yu Yen, ${ }^{1}$ Tao-Hsing Chen, ${ }^{2 *}$ Po-Hsun Lai, ${ }^{2}$ \\ Sheng-Lung Tu, ${ }^{1 * *}$ and Yun-Hwei Shen ${ }^{1}$ \\ ${ }^{1}$ Department of Resources Engineering, National Cheng Kung University, Tainan City 701, Taiwan \\ ${ }^{2}$ Department of Mechanical Engineering, National Kaohsiung University of Science and Technology, \\ Kaohsiung City 807, Taiwan
}

(Received May 29, 2021; accepted November 8, 2021)

Keywords: $\mathrm{Zr}$-doped $\mathrm{ZnO}$, annealing temperature, optical property, electrical property

We investigated the effects of the annealing temperature on the optoelectronic properties of $\mathrm{Zr}$-doped $\mathrm{ZnO}(\mathrm{ZZO})$ thin films deposited on glass substrates by radio frequency sputtering and annealed at 200,300 , and $400{ }^{\circ} \mathrm{C}$. It was found by X-ray diffraction analysis that all the deposited thin films had a hexagonal crystal structure with polycrystalline grains oriented along the $\left(\begin{array}{lll}0 & 0 & 2\end{array}\right)$ direction. Furthermore, the film annealed at $400{ }^{\circ} \mathrm{C}$ had the lowest resistivity among the films due to the growth of grains, as well as the lowest resistivity of $1.5 \times 10^{-2} \Omega \cdot \mathrm{cm}$, a mobility of $35 \mathrm{~cm}^{2} \mathrm{~V}^{-1} \mathrm{~s}^{-1}$, and a carrier concentration of $4.2 \times 10^{19} \mathrm{~cm}^{-3}$. It also had a maximum transmittance of $95 \%$ and an energy gap of $3.2 \mathrm{eV}$. These results show that ZZO thin films subjected to annealing at $400{ }^{\circ} \mathrm{C}$ are promising for use as stable photosensors.

\section{Introduction}

To meet the requirements of high-performance photosensors and solar cell applications, the development of transparent conducting oxides (TCOs) with enhanced electrical and optical characteristics is necessary. ${ }^{(1-3)}$ Zinc oxide has been widely utilized for domestic and industrial applications such as liquid crystal displays, light-emitting diodes, ${ }^{(4)}$ and sensors. ${ }^{(5-9)}$ Indium tin oxide (ITO) thin films were the first materials to be widely used in these electrical devices. However, $\mathrm{ZnO}$ is a TCO with a wide direct band gap of $\sim 3.37 \mathrm{eV}$ at room temperature (RT) and has low cost and toxicity, low electrical resistivity, and high optical efficiency. Furthermore, various growth techniques ${ }^{(10-12)}$ and metal elemental doping have been investigated with the aim of enhancing the electrical and optical properties of $\mathrm{ZnO}$ thin films. Elements such as $\mathrm{Al},{ }^{(13-15)}$ $\mathrm{Ga}^{(16,17)} \mathrm{Cu},{ }^{(18)}$ and $\mathrm{Mo}^{(19)}$ have been doped because the resulting ternary oxides can have useful characteristics that binary oxides cannot provide. ${ }^{(20)}$ ITO thin films are not stable in a hightemperature environment with temperatures above $400{ }^{\circ} \mathrm{C} .(21)$ In contrast, it has been reported that the electrical and chemical properties of $\mathrm{Zr}$-doped $\mathrm{ZnO}$ (ZZO) thin films are stable in high-

\footnotetext{
*Corresponding author: e-mail: thchen@nkust.edu.tw

**Corresponding author: e-mail: finytu@gmail.com https://doi.org/10.18494/SAM.2021.3706
} 
temperature environments. ${ }^{(22,23)}$ Thus, ZZO is a promising substitute for ITO that can be employed in devices operating at high temperatures. Furthermore, $\mathrm{Zr}^{4+}$ (ionic radius of $0.742 \AA$ ) and $\mathrm{Zn}^{2+}$ (ionic radius of $0.745 \AA$ ) ions have similar radii and $\mathrm{Zr}$ is an n-type doping impurity; thus, it can increase the carrier density in $\mathrm{ZnO}$ thin films. ${ }^{(24-26)}$

Many methods, such as sputtering, pulsed laser deposition (PLD), and the sol-gel method, ${ }^{(27,28)}$ can be used for depositing $\mathrm{ZnO}$ thin films. Sputtering is advantageous over the other methods for preparing uniform and large-area films with higher quality. However, ZZO thin films have seldom been prepared by sputtering, with very little literature available. ${ }^{(26)}$ The aim of this study was to prepare ZZO thin films by sputtering on Corning 1737 glass substrates, which was followed by annealing at different temperatures. We analyzed the effects of the annealing temperature on the structural, optical, and electrical properties of the films. We hope to develop highly efficient thin-film materials for photosensor and gas sensor applications.

\section{Material Preparation and Experimental Procedure}

ZZO films were deposited by RF sputtering on 1-mm-thick Corning 1737 glass substrates at RT using planar magnetrons in an Ar atmosphere (both $99.999 \%$ purity). The target was prepared from $\mathrm{ZnO}$ (99.99\% purity) and $\mathrm{Zr}$ (99.9\% purity) powders, and the $\mathrm{Zn}$ content of the target was $5 \mathrm{wt} \%$. The powders were mixed in a mechanical miller for $50 \mathrm{~min}$ then pressed into pellets and sintered at $1350{ }^{\circ} \mathrm{C}$ for $15 \mathrm{~h}$ in vacuum. Before depositing the thin film, the glass substrate was cleaned ultrasonically using methanol, acetone, and deionized water in sequence, then dried by blowing $\mathrm{N}_{2}$ gas. The deposition was performed using a sputtering power of $80 \mathrm{~W}$, a chamber pressure of mTorr, a deposition time of $45 \mathrm{~min}$, and a target-to-substrate distance of $5 \mathrm{~mm}$. Ar gas was introduced into the chamber at a flow rate of $15 \mathrm{sccm}$ (Ar). The target was pre-sputtered for more than 20 min to clean its surface before deposition. To achieve homogenous samples, all ZZO films were deposited while rotating the substrate. Following the deposition process, half of the samples were annealed at a temperature of 200,300 , or $400{ }^{\circ} \mathrm{C}$. The grain size growth was examined by X-ray diffraction (XRD, SIEMENS D-500) with $\mathrm{CuK}_{\alpha}$ radiation. The optical transmittance properties of the films were investigated using a UV-vis spectrophotometer (Hitachi 2900). The electrical properties were determined by Hall effect measurements (AHM-800B). Finally, the surface features and grain size of the films were characterized by field-emission scanning electron microscopy (SEM, HITACHI SU-5000).

\section{Results and Discussion}

\subsection{Structural characterization by XRD analysis}

XRD analysis was used to determine the structure of the ZZO thin films. The obtained XRD patterns are shown in Fig. 1. It can be seen that all the ZZO thin films are polycrystalline with a preferential orientation and a wurtzite structure. ${ }^{(29,30)} \mathrm{ZnO}(002)$ and (004) peaks were observed, with the intensity of the (004) peak being much lower than that of the (002) peak. The intensity of the (002) peak increased significantly with annealing temperature from as-deposited to 


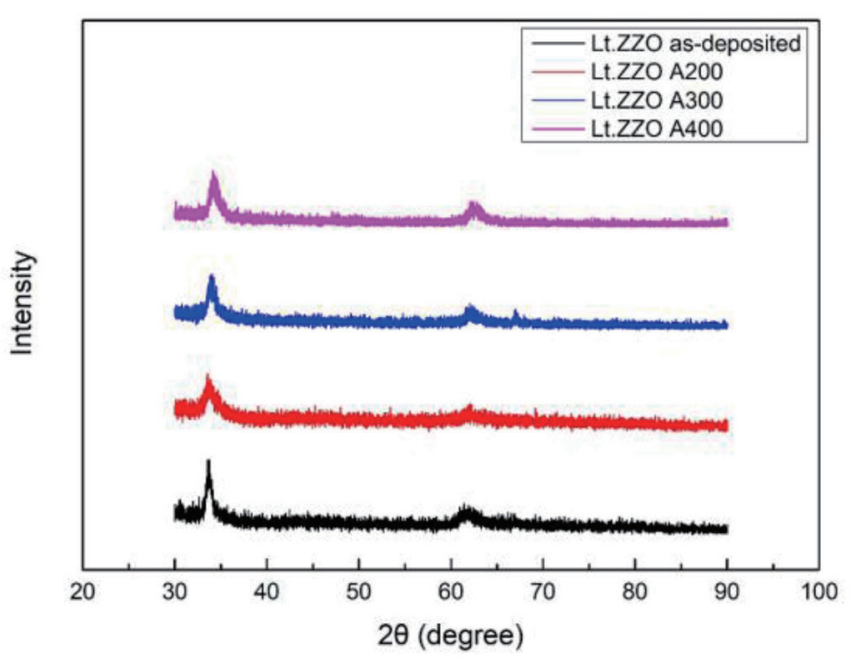

Fig. 1. (Color online) XRD patterns of ZZO films as a function of annealing temperature.

$400{ }^{\circ} \mathrm{C}$. These results indicate that the grain size of the ZZO films increased with annealing temperature owing to the reduced structural distortion, but the preferential orientation of the ZZO films was not affected by the annealing temperature.

\subsection{Analysis of electrical properties}

The electrical properties of the ZZO thin films were evaluated by Hall measurements. The resistivity of the as-deposited films was found to be very high. This means that a large number of oxygen vacancies were present at both the grain boundaries and surfaces of the films. A large number of oxygen vacancies may produce a potential barrier that hinders the electrical transport, causing a reduction in conductivity. When the annealing temperature was $400{ }^{\circ} \mathrm{C}$, the dopants located at the interstitial sites of the $\mathrm{ZnO}$ films were activated, which enhanced the conductivity. From Table 1, it can be seen that the resistivity decreased to $1.5 \times 10^{-2} \Omega \cdot \mathrm{cm}$ at the annealing temperature of $400{ }^{\circ} \mathrm{C}$. Furthermore, the free carrier concentration also increased with annealing temperature, which contributed to the occupation of interstitial positions in the $\mathrm{ZnO}$ matrix. The resistivity of the deposited films was also affected by the film grain size. The low resistivity was ascribed to the increase in grain size as discussed later. ${ }^{(31)}$

Table 1

Variations of resistivity, mobility, and carrier concentration of ZZO thin films annealed at different temperatures.

\begin{tabular}{lccc}
\hline $\begin{array}{l}\text { Annealing temperature } \\
\left({ }^{\circ} \mathrm{C}\right)\end{array}$ & $\begin{array}{c}\text { Resistivity } \\
(\Omega \cdot \mathrm{cm})\end{array}$ & $\begin{array}{c}\text { Mobility } \\
\left(\mathrm{cm}^{2} / \mathrm{Vs}\right)\end{array}$ & $\begin{array}{c}\text { Carrier concentration } \\
\left(\mathrm{cm}^{-3}\right)\end{array}$ \\
\hline As-deposited & 1.17 & 8.17 & $7.52 \times 10^{18}$ \\
200 & $1.86 \times 10^{-1}$ & 22.4 & $1.28 \times 10^{19}$ \\
300 & $7.51 \times 10^{-2}$ & 28 & $3.57 \times 10^{19}$ \\
400 & $1.5 \times 10^{-2}$ & 35 & $4.2 \times 10^{19}$ \\
\hline
\end{tabular}




\subsection{Optical properties of $\mathrm{ZZO}$ thin films annealed at different temperatures}

Figure 2 presents the transmittance in the wavelength region of 350 to $800 \mathrm{~nm}$ for the $\mathrm{ZZO}$ thin films subjected to annealing at different temperatures. It can be clearly seen that the transmittance of all the ZZO films was high (over 90\%) with a negligible effect of the annealing temperature on the transmittance. This means that annealing is not useful for improving the transmittance of ZZO thin films in the visible range, but it can increase the conductivity of the films. All the ZZO films had a sharp absorption edge in the UV range of 300-400 $\mathrm{nm}$. The optical band gap $\left(E_{g}\right)$ was determined by the extrapolation of the linear region of the plot of the square of the absorption coefficient $\alpha^{2}$ versus the photon energy $h v$. Thus, $E_{g}$ can be obtained from the following equation: ${ }^{(32)}$

$$
(\alpha h v)^{2}=A\left(h v-E_{g}\right)
$$

where $h$ is Planck's constant, $v$ is the frequency of incident photons, and $A$ is an energyindependent constant. Figure 3 shows the relationship between $(\alpha h v)^{2}$ and the optical band gap for the ZZO thin films annealed at different temperatures. Table 2 shows that $E_{g}$ increases from 3.18 to $3.25 \mathrm{eV}$ with annealing temperature.

It is thus observed that the band gap of the ZZO thin films increases with annealing temperature. The carrier concentration also increases with annealing temperature (see Table 1), which can be explained by the Burstein-Moss shift. ${ }^{(33,34)}$

\subsection{Morphological and structural analyses of ZZO thin films}

The surface morphologies of the ZZO films (see Fig. 4) annealed at different temperatures were obtained by SEM. With increasing annealing temperature from RT to $400{ }^{\circ} \mathrm{C}$, the surface

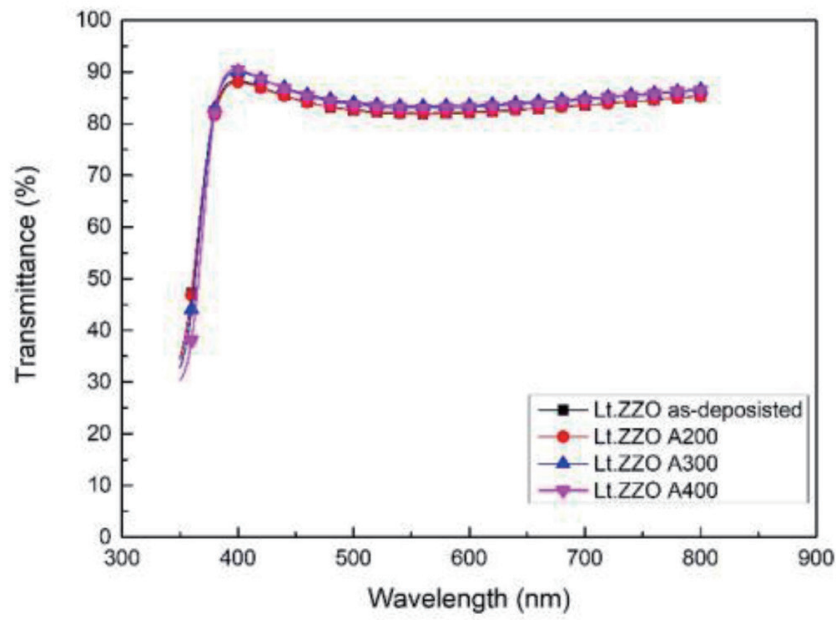

Fig. 2. (Color online) Optical transmittances of ZZO thin films annealed at different temperatures.

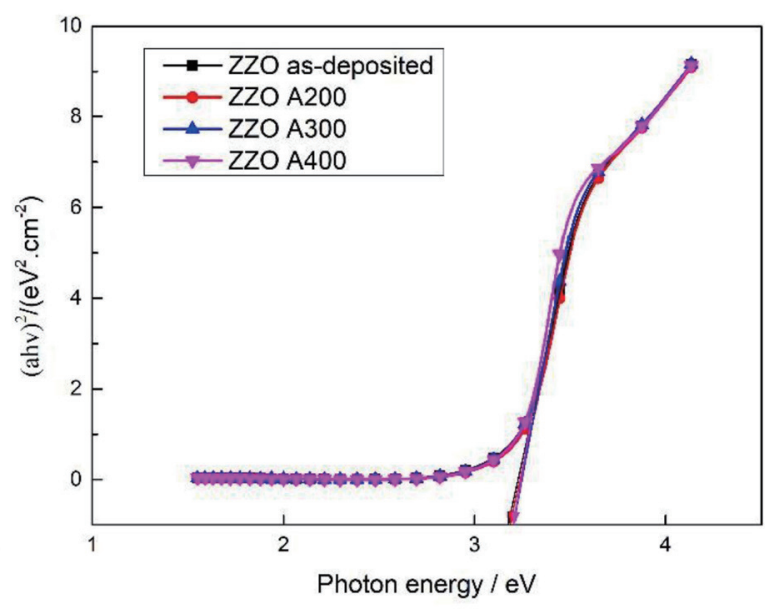

Fig. 3. (Color online) Optical band gaps of ZZO thin films annealed at different temperatures. 
Table 2

Energy gaps of ZZO thin films under different annealing temperatures.

\begin{tabular}{lc}
\hline Annealing temperature $\left({ }^{\circ} \mathrm{C}\right)$ & Energy gap $(\mathrm{eV})$ \\
\hline As-deposited & 3.18 \\
200 & 3.20 \\
300 & 3.22 \\
400 & 3.25 \\
\hline
\end{tabular}

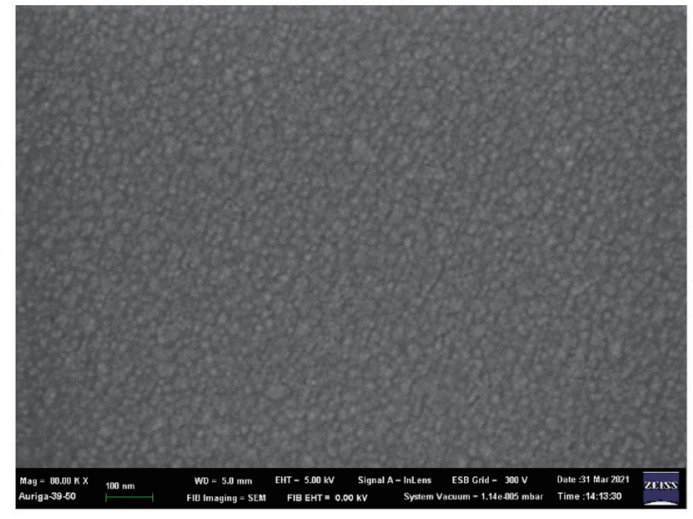

(a)

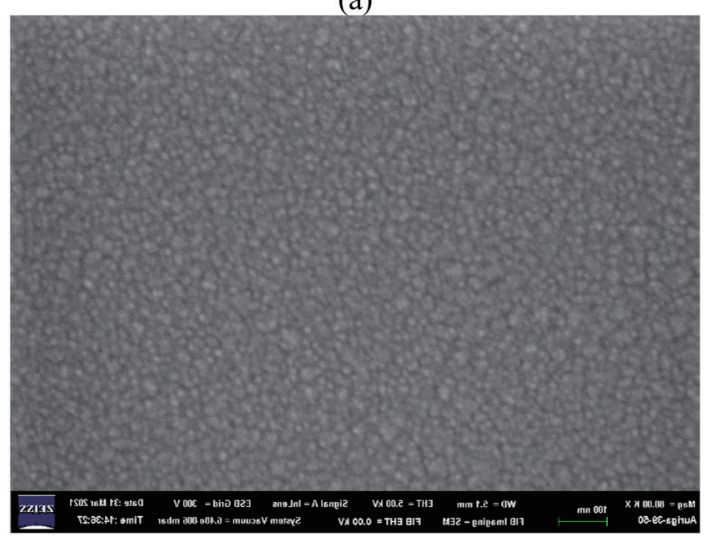

(c)

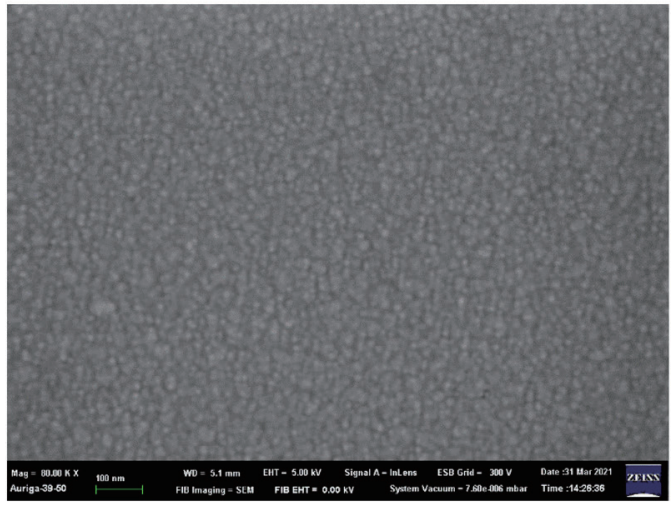

(b)

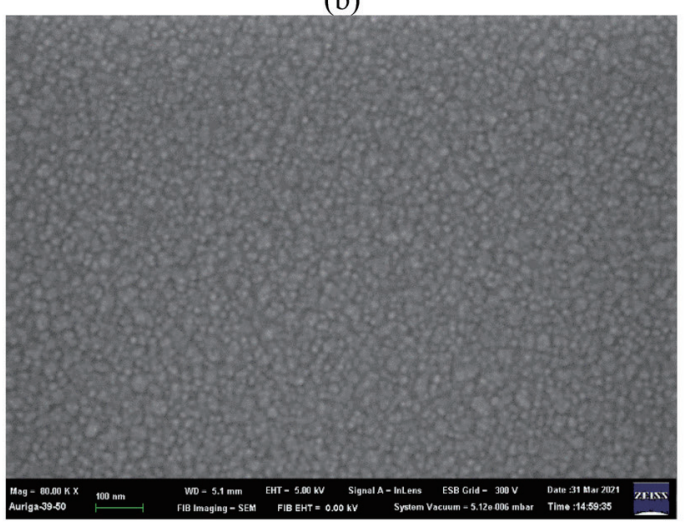

(d)

Fig. 4. (Color online) SEM images of (a) as-deposited ZZO thin films and films annealed at (b) 200, (c) 300, and (d) $400{ }^{\circ} \mathrm{C}$.

becomes smooth and dense, indicating improved crystallinity. Scherrer's formula was used to calculate the grain size of ZZO:(35)

$$
D=0.9 \lambda / \beta \cos \theta
$$

where $D$ is the grain size, $\lambda$ is the wavelength of the $\mathrm{CuK}_{\alpha}$ line, $\beta$ is the full width at half maximum (FWHM) in radians, and $\theta$ is the Bragg angle. Table 3 lists the grain sizes and FWHM values of the ZZO thin films annealed at different temperatures. As expected from 
Table 3

Grain sizes and FWHM values of ZZO thin films annealed at different temperatures.

\begin{tabular}{lcc}
\hline Annealing temperature $\left({ }^{\circ} \mathrm{C}\right)$ & FWHM & Grain size $(\mathrm{nm})$ \\
\hline As-deposited & 0.85 & 12 \\
200 & 0.82 & 15 \\
300 & 0.8 & 19 \\
400 & 0.78 & 21 \\
\hline
\end{tabular}

Eq. (2), the grain size in the films increases with decreasing FWHM. As mentioned above, the resistivity decreases with increasing annealing temperature, which may be due to the increase in grain size, which is confirmed from Table 3.

\section{Conclusions}

We investigated the effects of the annealing temperature of ZZO films deposited on Corning glass substrates on their structural, electrical, and optical properties. The resistivity deceased as the annealing temperature in vacuum increased from as-deposited to $400{ }^{\circ} \mathrm{C}$ owing to the improved grain size. The film annealed at the optimum annealing temperature of $400{ }^{\circ} \mathrm{C}$ had the lowest resistivity of $1.5 \times 10^{-2} \Omega \cdot \mathrm{cm}$ and a high transmittance above $90 \%$ in the visible range. Although the film annealed at $400{ }^{\circ} \mathrm{C}$ had the highest conductivity, the transmittances of the ZZO films were similar regardless of the annealing temperature and similar to that of the asdeposited film. Furthermore, the energy gap increased slightly from $3.18 \mathrm{eV}$ for the as-deposited film to $3.25 \mathrm{eV}$ for the film annealed at $400{ }^{\circ} \mathrm{C}$. The grain size increased with annealing temperature owing to the enhanced grain size growth at higher temperatures. Hence, the ZZO films have potential use in optoelectronic sensor applications.

\section{Acknowledgments}

The authors gratefully acknowledge the financial support provided to this study by the Ministry of Science and Technology, Taiwan, under Project Nos. MOST 109-2221-E-992-010, MOST 110-2628-E-992-002, and MOST 110-2731-M-006-001.

\section{References}

1 K. Fleischer, E. Arca, and I. V. Shvets: Sol. Energy Mater. Sol. Cells 101 (2012) 262. https://doi.org/10.1016/j. solmat.2012.01.037

2 M. Nisha, S. Anusha, A. Antony, R. Manoj, and M. K. Jayaraj: Appl. Surf. Sci. 252 (2005) 1430. https://doi. org/10.1016/j.apsusc.2005.02.115

3 C. Li, C. Han, Y. Zhang, Z. Zang, M. Wang, X. Tang, and J. Du: Sol. Energy Mater. Sol. Cells 172 (2017) 341. https://doi.org/10.1016/j.solmat.2017.08.014

4 C. F. Liu, T. H. Chen, and J. T. Huang: Sens. Mater. 32 (2020) 3727. https://doi.org/10.18494/SAM.2020.3138

5 P. Nunes, E. Fortunato, P. Tonello, F. B. Fernandes, P. Vilarinho, and R. Martins: Vacuum 64 (2002) 281. https://doi.org/10.1016/S0042-207X(01)00322-0

6 F. H. Wang and C. L. Chang: Appl. Surf. Sci. 370 (2016) 83. https://doi.org/10.1016/j.apsusc.2016.02.161

7 T. H. Chen and H. T. Su: Sens. Mater. 30 (2018) 2541. https://doi.org/10.18494/SAM.2018.2056

8 T. H. Chen and C. L. Yang: Opt. Quantum Electron. 48 (2016) 533. https://doi.org/10.1007/s11082-016-0808-3 
9 T. H. Chen and T. Y. Chen: Nanomaterials 5 (2015) 1831. https://doi.org/10.3390/nano5041831

10 S. B. Qadri, H. Kim, J. S. Horwizt, and D. B. Chrisey: J. Appl. Phys. 88 (2000) 6564. https://doi. org/10.1063/1.1320032

11 G. K. Paul, S. Bandyopadhyay, S. K. Sen, and S. Sen: Mater. Chem. Phys. 79 (2003) 71. https://doi.org/10.1016/ $\underline{\text { S0254-0584(02)00454-6 }}$

12 K. Behedi, M. Addou, M. E. Jouad, S. Bayoud, and Z. Sofiani: Appl. Surf. Sci. 255 (2009) 9054. https://doi. org/10.1016/j.apsusc.2009.06.130

13 J. Hu and R. G. Gordon: J. Appl. Phys. 71 (1992) 880. https://doi.org/10.1063/1.351309

14 J. F. Chang and M. H. Hon: Thin Solid Films 386 (2001) 79. https://doi.org/10.1016/S0040-6090(00)01891-5

15 M. Kumar, L. Wen, B. B. Sadhu, and J. G. Han: Appl. Phys. Lett. Sci. 106 (2015) 241903. https://doi. org $/ 10.1063 / 1.4922732$

16 T. P. Rao and M. C. S. Kumar: J. Alloy. Compd. 506 (2010) 788. https://doi.org/10.1016/j.jallcom.2010.07.071

17 B. D. Ahn, S. H. Oh, C. H. Lee, G. H. Kim, H. J. Kim, and S. Y. Lee: J. Cryst. Growth 309 (2007) 128. https:// doi.org/10.1016/j.jcrysgro.2007.09.014

18 N. E. Sung, I. J. Lee, A. Thakur, K. H. Chae, H. J. Shin, and H.-K. Lee: Mater. Res. Bull. 47 (2012) 2891. https:// doi.org/10.1016/j.materresbull.2012.04.103

19 M. Wu, S. Yu, G. Chen, L. He, L. Yang, and W. Zhan: Appl. Surf. Sci. 324 (2015) 791. https://doi.org/10.1016/j. apsusc.2014.11.039

20 S. Ishibashi, Y. Higuchi, Y. Ota, and K. Nakamura: J. Vac. Sci. Technol., A 8 (1990) 1403. https://doi. org/10.1116/1.576890

21 S. B. Qadri, H. Kim, H. R. Khan, A. Piqué, J. S. Horwitz, D. Chrisey, W. J. Kim, and E. F. Skelton: Thin Solid Films 750 (2000) 377. https://doi.org/10.1016/S0040-6090(00)01285-2

22 M. Lv, X. Xiu, Z. Pang, Y. Dai, L. Ye, C. Cheng, and S. Han: Thin Solid Films 516 (2008) 2017. https://doi. org/10.1016/j.tsf.2007.06.173

23 H. Zhang, H. Liu, and L. Feng: Vacuum 84 (2010) 833. https://doi.org/10.1016/j.vacuum.2009.11.005

24 N. E. Sung, M. A. Marcus, K. S. Lee, H. J. Yun, and I. J. Lee: Thin Solid Films 696 (2020) 137782. https://doi. org/10.1016/j.tsf.2019.137782

25 V. Gokulakrishnan, S. Parthiban, K. Jeganathan, and K. Ramamurthi: Appl. Surf. Sci. 257 (2011) 9068. https:// doi.org/10.1016/j.apsusc.2011.05.102

26 N. E. Sung, K. S. Lee, and I. J. Lee: Thin Solid Films 651 (2018) 42. https://doi.org/10.1016/j.tsf.2018.02.011

27 C. F. Liu, T. H. Chen, and Y. S. Huang: Sens. Mater. 32 (2020) 2321. https://doi.org/10.18494/SAM.2020.2867

28 C. F. Liu, C. H. Kuo, T. H. Chen, and Y. S. Huang: Coatings 10 (2020) 394. https://doi.org/10.3390/ coatings10040394

29 G. K. Paul, S. Bandyopadhyay, S. K. Sen, and S. Sen: Mater. Chem. Phys. 79 (2003) 71. https://doi.org/10.1016/ S0254-0584(02)00454-6

30 JCPDS, International Centre for Diffraction Data Standards, Card No. 36-1451.

31 B. H. Choi, H. B. Im, J. S. Song, and K. H. Yoon: Thin Solid Films 712 (1990) 193. https://doi.org/10.1016/00406090(90)90223-Z

32 S. Venkatachalam, Y. Iida, and Y. Kanno: Superlattices Microstruct. 44 (2008) 127. https://doi.org/10.1016/j. spmi.2008.03.006

33 E. Burstein: Phys. Rev. Lett. 93 (1954) 632. https://doi.org/10.1103/PhysRev.93.632

34 I. Hamberg and C. G. Granqvist: J. Appl. Phys. 60 (1986) R123. https://doi.org/10.1063/1.337534

35 M. Caglar, S. Ilican, and Y. Caglar: Thin Solid Films 517 (2009) 5023. https://doi.org/10.1016/j.tsf.2009.03.037

\section{About the Authors}

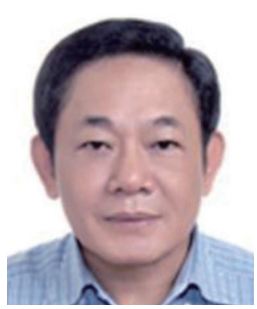

Ming-Yu Yen graduated with an EMBA from National Sun Yat-sen University in 2015. He has been studying under the human resource management Ph.D. program of National Sun Yat-sen University and the resources engineering Ph.D. program of National Chen Kung University since 2015 and 2017, respectively. 


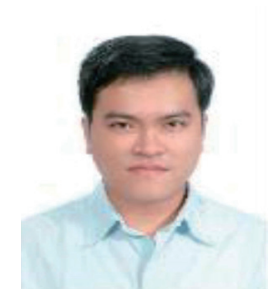

Tao-Hsing Chen received his B.S. degree from National Cheng Kung University, Taiwan, in 1999 and his M.S. and Ph.D. degrees from the Department of Mechanical Engineering, National Cheng Kung University, in 2001 and 2008, respectively. From August 2008 to July 2010, he was a postdoctoral researcher at the Center for Micro/Nano Science and Technology, National Cheng Kung University. In August 2010, he became an assistant professor at National Kaohsiung University of Applied Sciences (renamed National Kaohsiung University of Science and Technology), Taiwan. Since 2016, he has been a professor at National Kaohsiung University of Science and Technology. His research interests are in metal materials, TCO thin films, thermal sensors, and photosensors. (thchen@nkust.edu.tw)

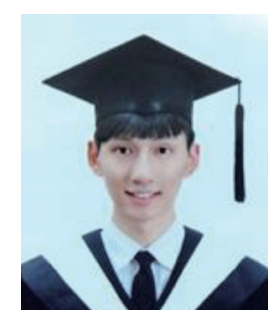

Po-Hsun Lai received his B.S. degree from National Kaohsiung University of Science and Technology, Taiwan, where he is currently studying toward his M.S. degree. His research interests are in MEMS, materials engineering, and sensors.

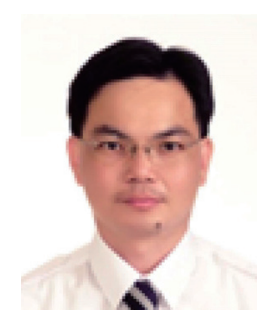

Sheng-Lung Tu received his M.S. degree from the Department of Mechanical Engineering, National Cheng Kung University in 2010 and his Ph.D. degree from the Department of Resources Engineering, National Cheng Kung University in 2014. Since 2014, he has worked as a general affairs officer at National Cheng Kung University. His research interests are in PVD technology, thin-film technology, and sensors.

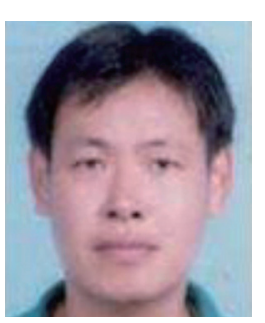

Yun-Hwei Shen received his B.S. degree from the Department of Mineral and Petroleum Engineering, National Cheng Kung University in 1982, his M.S. degree from the Department of Mineral Preparation Engineering, University of Alaska Fairbanks, USA, in 1987, and his Ph.D. degree from the Department of Environmental Engineering, Penn State University, USA in 1992. Since 1999, he has been a professor at the Department of Resources Engineering, National Cheng Kung University. His research interests are in catalysis technology, the hydrometallurgical processing of resource materials, sensors, and hydrometallurgical processes. 